\title{
May the Neutrophil Lymphocyte Ratio be a New Marker for Uveitis Development in Ankylosing Spondylitis?
}

\author{
Zeynep YILMAZ BOZKURT, Ediz DALKILIÇ¹ \\ ${ }^{1}$ Bursa Uludağ University Faculty of Medicine, Department of Internal Medicine, Division of Rheumatology, Bursa, Turkey
}

Turk J Int Med 2021;3(Supplement 1):S36-S37

DOI: $\underline{10.46310 / \text { tjim.876917 }}$

Keywords: Ankylosing spondylitis, disease activity, neutrophil lymphocyte ratio, uveitis

Spondyloarthropathies (SpA) includes several rheumatic disorders that share clinical, genetic and radiographic features. Ankylosing Spondylitis (AS) is an autoimmune disease of unknown cause belonging to the group of spondyloarthritides associated with the human leucocyte antigen (HLA)-B27. It is a chronic, progressive, multi-system inflammatory disorder which primarily involves the sacroiliac (SI) joints and the axial skeleton. Peripheral joints and tendons can also be affected. Inflammatory low back pain is main symptom for diagnosis of AS. Although, the etiology is unknown, but there is evidence about genetic predisposition, HLA-B27 gene is commonly present. The prevalence of AS is variable, the disease is more common in Caucasians than in other races. Typically, the prevalence of AS in a population reflects the associated prevalence of HLA-B27 gene in that population. ${ }^{1}$ A recent study reported a mean AS prevalence per 10,000 population as 23.8 cases in Europe, 16.7 in Asia, 31.9 in North America, 10.2 in Latin America and 7.4 in Africa. ${ }^{2}$ Inflammation of the anterior uveal tract is known as anterior uveitis or iritis. Acute anterior uveitis (AAU) is the typical uveitis associated with SPA and is the most common extraarticular clinical feature of SPA. AAU occurs in about $25 \%$ to $40 \%$ of patients with $\mathrm{AS}^{3}$ of whom approximately $90 \%$ are HLAB27 positive. ${ }^{4}$ Neutrophil-lymphocyte ratio (NLR) is a marker that has been researched in recent years to be used as a marker of inflammation. The aim of our study is to evaluate the NLR in AS patients with uveitis, which is an extraarticular involvement, while having uveitis and to compare it with the NLR at first admission.

Ninety patients with uveitis and diagnosed with AS according to the modified New York Criteria were included in the study. The files of the patients were analyzed retrospectively. Demographic data and laboratory parameters were recorded. NLR was calculated arithmetically using neutrophil and lymphocyte values in complete blood count. $53(58.9 \%)$ of the patients were male, $37(41.1 \%)$ were female. The mean age was $42.51 \pm 9.23$ years in male, $45.84 \pm 9.78$ years in female, the mean

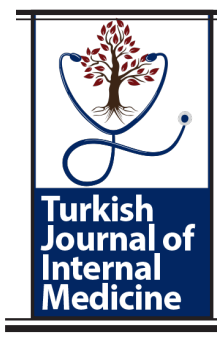

Received:February 08, 2021;Accepted:March 4, 2021;Published Online:March 6, 2021

Bursa Uludağ University Faculty of Medicine, Department of Internal Medicine, Division of 
duration of diagnosis was $14.53 \pm 10.34$ years in male, $10.84 \pm 6.01$ years in female, and the mean body mass index (BMI) was $27.61 \pm 3.53 \mathrm{~kg} / \mathrm{m}^{2}$ in male and $25.82 \pm 3.12 \mathrm{~kg} / \mathrm{m}^{2}$ in female. There was no significant difference between the genders in terms of age, duration of diagnosis, and BMI $(p=0.104, p=0.073, p=0.557$, respectively). No significant difference was found between genders in terms of NLR values at first admission and at the time of uveitis $(p=0.016)$. There was a significant difference between the NLR values $(1.660 \pm 0.67$ and $2.623 \pm 1.293$, respectively) in both genders at first admission and at the time of uveitis $(p<0.001)$.

In studies, erythrocyte sedimentation rate (ESR), C-reactive protein (CRP) and Bath Ankylosing Spondylitis Disease Activity Index (BASDAI) are used as activation indicators. There are studies in the literature showing that NLR is an important marker for determining disease activity and inflammation in AS patients. Gokmen et al. compared the NLR of AS patients with healthy individuals in their study. Together with acute phase reactants such as CRP, it has been found to be a useful marker in showing inflammation. ${ }^{5}$ In the meta-analysis of Shanshan Xu et al. including 10 studies, it was shown that NLR is a marker that can be used to show systemic inflammation in AS patients compared to healthy controls. ${ }^{6}$ In the study of Kucuk et al. ${ }^{7}$, NLR was found to be significantly higher in AS patients with severe disease activity than in AS patients with mild disease activity. In the study conducted by Coskun et al. ${ }^{8}$, In AS patients with high disease activity, NLR was found to be significantly lower in the $3^{\text {rd }}$ month of the treatment compared to the start of treatment with an anti-tumor necrosis factor drug (antiTNF). Uveitis is an extraarticular manifestation seen in $25 \%$ to $40 \%$ of AS patients. It is correlated with disease activity. In the literature, there is no study about NLR comparison in AS patients with developing uveitis. In our study, we compared the NLR values of AS patients at the first admission and at the time of having uveitis. We found that NLR was significantly higher in both genders while having uveitis.

In conclusion NLR can be used as a marker for the development of uveitis in AS patients and correlates with disease activity.

\section{Conflict of Interests}

Authors declare that there are none.

\section{Acknowledgment}

This study has been presented in $17^{\text {th }}$ Uludag Internal Medicine National Winter Congress, $6^{\text {th }}$ Bursa Family Medicine Association National Congress, $11^{\text {th }}$ Uludag Internal Medicine Nursing Congress, 5-7 March 2021, Bursa, Turkey.

\section{References}

1. Khan MA. Epidemiology of HLA-B27 and arthritis. Clin Rheumatol. 1996 Jan;15 Suppl 1:10-2. doi: 10.1007/BF03342637.

2. Dean LE, Jones GT, MacDonald AG, Downham C, Sturrock RD, Macfarlane GJ. Global prevalence of ankylosing spondylitis. Rheumatology (Oxford). 2014 Apr;53(4):650-7. doi: 10.1093/rheumatology/ket387.

3. Stolwijk C, van Tubergen A, Castillo-Ortiz JD, Boonen A. Prevalence of extra-articular manifestations in patients with ankylosing spondylitis: a systematic review and meta-analysis. Ann Rheum Dis. 2015 Jan;74(1):6573. doi: 10.1136/annrheumdis-2013-203582.

4. Zeboulon N, Dougados M, Gossec L. Prevalence and characteristics of uveitis in the spondyloarthropathies: a systematic literature review. Ann Rheum Dis. 2008 Jul;67(7):955-9. doi: 10.1136/ard.2007.075754.

5. Gökmen F, Akbal A, Re $\square$ orlu H, Gökmen E, Güven M, Aras AB, Erba $\square$ G, Kömürcü E, Akbal E, Co $\square$ ar M. Neutrophil-lymphocyte ratio connected to treatment options and inflammation markers of ankylosing spondylitis. J Clin Lab Anal. 2015 Jul;29(4):294-8. doi: $10.1002 /$ jcla.21768.

6. Xu S, Ma Y, Wu M, Zhang X, Yang J, Deng J et al. Neutrophil lymphocyte ratio in patients with ankylosing spondylitis: A systematic review and metaanalysis. Mod Rheumatol. 2020 Jan;30(1):141-8. doi: 10.1080/14397595.2018.1564165.

7. Kucuk A, Uslu AU, Ugan Y, Bagcaci S, Karahan AY, Akarmut $A$ et al. Neutrophil-to-lymphocyte ratio is involved in the severity of ankylosing spondylitis. Bratisl Lek Listy. 2015;116(12):722-5. doi: 10.4149/ bl1_2015_142.

8. Co $\square$ kun BN, Öksüz MF, Ermurat S, Tufan AN, Oruço $\square$ lu N, Do $\square$ an A, Dalkılıç E, Pehlivan Y. Neutrophil lymphocyte ratio can be a valuable marker in defining disease activity in patients who have started anti-tumor necrosis factor (TNF) drugs for ankylosing spondylitis. Eur J Rheumatol. 2014 Sep;1(3):101-105. doi: 10.5152/eurjrheumatol.2014.034. 